\title{
PROPOSED A COMPACT MULTIBAND AND BROADBAND RECTANGULAR MICROSTRIP PATCH ANTENNA FOR C-BAND AND X- BAND
}

Rahul Tiwari,Seema Verma

PhD Research Scholar Department of Electronics Engineering Banasthali Vidyapeeth, Banasthali rahulcktd@gmail.com

Associate Professor Department of Electronics Engineering Banasthali Vidyapeeth, Banasthali Seemaverma3@yahoo.com

\begin{abstract}
In this communication two proposed antenna described one for broadband at $6.71445 \mathrm{GHz}$ to $11.9362 \mathrm{GHz}$ with finite ground plane. The antenna designed with $11.4051 \mathrm{~mm} \times 8.388 \mathrm{~mm}$ radiating copper patch with ground plane design with $21.0051 \mathrm{~mm} \times 17$. $988 \mathrm{~mm}$. And this Compact broadband rectangular shape microstrip patch antenna is designed and analyzed for the return loss of $-20.08 \mathrm{~dB}$ is achieved at the resonant frequency of $7.941 \mathrm{GHz}$, From Antenna2-it is observed that, antenna for multiband at different frequency. The primary radiating elements are Simple Rectangular Microstrip Patch Antenna in upper side with probe feed and use finite ground plane are two parallel crossed printed slot for three different frequency applications which is smaller in size compared to other available multiband antennas. From the result, it is observed that, the return loss of $-16.97 \mathrm{~dB}$ is achieved at the first resonant frequency of $4.853 \mathrm{GHz},-10.30 \mathrm{~dB}$ at the second resonant frequency of $8.382 \mathrm{GHz},-10.73 \mathrm{~dB}$ at the third resonant frequency of $9.265 \mathrm{GHz},-17.38 \mathrm{~dB}$ at the fourth resonant frequency of $10.15 \mathrm{GHz}$ and $-12.37 \mathrm{~dB}$ at the fifth resonant frequency of $11.91 \mathrm{GHz}$. This broadband and multi-band highly efficient antenna for use in C-Band, and X-Band.
\end{abstract}

\section{Indexing terms/Keywords}

Rectangular Patch Antenna, Finite Ground Plane, broadband, Multiband, C-band Application and X-band Application, IE3D Software, Impedance Matching.

\section{Council for Innovative Research}

Peer Review Research Publishing System

Journal: INTERNATIONAL JOURNAL OF COMPUTERS \& TECHNOLOGY

Vol. 13, No. 3

editorijctonline@gmail.com

cirworld.org/journals 


\section{INTRODUCTION}

Wireless technology is one of the main keyword of research in the whole world of communication systems recent years and a study of communication systems is incomplete without an understanding of the operation of trasmitts and receives electromagnetic waves like as antennas. [4]. Microstrip patch antennas have become the most favourite choice of antenna designers because of advantages such as, light weight, easy fabrication, easy integration with circuits and low profile. Intensive research is going on to develop bandwidth enhancement techniques by keeping its compact size small. The IEEE C-band and X-band is a portion of the electromagnetic spectrum in the microwave range of frequencies ranging from 4.1 to $8.0 \mathrm{GHz}$. And 8.1 to $12 \mathrm{GHz}$.

These frequency ranges that are used for many satellite communications, some Wi-Fi devices, some cordless telephones, and some weather radar systems. In the satelite communication is used The C-band is primarily in level, whether for fulltime satellite Television networks although subscription programming also exist. This use contrasts with direct broadcast satellite, which is a completely closed system used to deliver subscription programming to small satellite dishes that are connected with proprietary receiving equipment. In recent years, demand for small antennas for wireless communication has increased the interest of research work on the compact microstrip antenna design among for satellite Communication and Radar Engineers. Nowadays, in radar and satellite communication applications, microstrip patch antennas are very popular due to their low profile, mechanically robust, relatively compact and light and the possibility of Multiband frequency operation. Increasing progress in communication system increases the demand of compact, cost effective and easily fabricated antennas. So, this requirement of present time is full-filled by the invention of patch antenna [1].

Recently, multiband patch antennas have been investigated because of exposure of many wireless communication services such as GSM, Satellite Communication, CDMA and PCS [2, 3]. The Microstrip patch antenna can be fed by various techniques which are Probe feed, microstrip line feed, proximity coupled feed and aperture/slot-coupled feed. Among all the advantages, there are a few drawbacks of using patch antenna which is low gain, narrow bandwidth, high ohmic losses and low efficiency. A wideband microstrip patch antenna which also allowed multiband properties by designing a Two Crossed Slot on the finite Ground Plane and Impedance Matching to the Single Stub was presented in this Paper. This technique gives better efficiency and gain, operating at different bands which are $4.85 \mathrm{GHz}, 8.382 \mathrm{GHz}$, $9.265 \mathrm{GHz}, 10.15 \mathrm{GHz}$, and $11.91 \mathrm{GHz}$, respectively. According to the presented results, it includes two satellite communication bands which are $\mathrm{C}$ and $\mathrm{X}$-band. These bands are also widely used in satellite and radar communication.

Microstrip antennas for use as a low profile flush mounted antennas on rockets and missiles showed that this was a practical concept for use in many antenna system problems. Various mathematical models were developed for this antenna and its applications were extended to many other fields. Technology has been developing day by day where satellite communication is becoming a daily part of our life. As the technological devices are getting smaller demand for multiband operating antennas are growing faster to the consumers.

\section{DESIGN METHODOLOGY AND SIMULATION OF PROPOSED ANTENNA STRUCTURE}

The material with dielectric constant 4.4 (FR4 Epoxy) is used as a backplane conductor to form Microstrip antenna. The configuration of the conventional printed antenna is shown in Figure 1 with $L=8.388 \mathrm{~mm}, \mathrm{~W}=11.4051 \mathrm{~mm}$, substrate thickness $\mathrm{h}=1.6 \mathrm{~mm}$, dielectric constant $\varepsilon r=4.4$. The coaxial probe - feed is located at $\mathrm{y}=\mathrm{W} / 2=11.4051 / 2=5.70255 \mathrm{~mm}$ and $x=\frac{L}{2 \sqrt{\epsilon_{\mathrm{r}}}} \quad=2 \mathrm{~mm}$ and Ground Plane Design $\mathrm{Lg}=6 \mathrm{~h}+\mathrm{L}=6 \times 1 . \quad 6+8.388=17.988 \mathrm{~mm}, \quad W g=6 \mathrm{~h}+\mathrm{W}=6 \times 1$. $6+11.4051=21.0051 \mathrm{~mm}$.

The heart of a microstrip patch antenna is the upper conductor. The patch of finite dimensions. The patch can be considered to be an open-ended transmission line of length and width. The amplitude of surface currents becomes significant when the signal frequency is close to resonance by taking only the fundamental mode into account. The resonant frequency can be calculated by

$$
\mathrm{f}_{\mathrm{o}}=\frac{\mathrm{c}}{2(\mathrm{~L}+2 \Delta \mathrm{L}) \sqrt{\varepsilon_{\text {reff }}}}
$$

Where $\Delta \mathrm{L}$ is the equivalent length extension that financial records for the fringing fields at the two open ends and $\varepsilon_{\text {reff }}$ Is the effective relative permittivity. A microstrip structure is not homogeneous because the electromagnetic field extends over the two media air and dielectric. Therefore wave propagation cannot be TEM. Since wave in two media travels with different velocities and the boundary conditions force nonzero transverse electric or magnetic components.

RMPA parametric analysis

Width of metallic patch $(\mathrm{W})$

$$
W=\frac{1}{2 f_{r} \sqrt{\mu_{0} \varepsilon_{0}}} \sqrt{\frac{2}{\varepsilon_{r}+1}}=\frac{C}{2 f_{r}} \sqrt{\frac{2}{\varepsilon_{r}+1}}
$$

Where,

$\mathrm{C}=$ free space velocity of light

$\varepsilon_{\mathrm{r}}=$ Dielectric constant of substrate 
Effective dielectric constant is calculated from:

$$
\varepsilon_{\text {eff }}=\frac{\varepsilon_{\mathrm{r}}+1}{2}+\frac{\varepsilon_{\mathrm{r}}-1}{2}\left(\frac{1}{\sqrt{1+\frac{12 \mathrm{~h}}{\mathrm{w}}}}\right)
$$

Length of metallic patch $(\mathrm{L}) \mathrm{L}=$ Leff $-2 \Delta \mathrm{L}$,

$$
\text { Where Leff }=\frac{\mathrm{C}}{2 \mathrm{f}_{\mathrm{r}} \sqrt{\varepsilon_{\text {eff }}}}
$$

Calculation of Length Extension

$$
\frac{\Delta \mathrm{L}}{\mathrm{h}}=0.412 \frac{\left(\varepsilon_{\text {eff }}+0.3\right)\left(\frac{\mathrm{w}}{\mathrm{h}}+0.264\right)}{\left(\varepsilon_{\text {eff }}-0.258\right)\left(\frac{\mathrm{w}}{\mathrm{h}}+0.8\right)}
$$

If $V_{i}$ is the amplitude of the incident wave and $V_{r}$ that of the reflected wave, then the return loss can be expressed in terms of the reflection coefficient $r$ as:

$$
\mathrm{R}_{\mathrm{L}}=-20 \log |\Gamma|,
$$

and the reflection coefficient $r$ can be expressed as:

$$
\Gamma=\frac{\mathrm{V}_{\mathrm{r}}}{\mathrm{V}_{\mathrm{i}}}
$$

For an antenna to radiate effectively, the return loss should be less than $-10 \mathrm{~dB}$.

Impedance Matching Analysis: Impedance Matching was originally developed for electrical power, but can be applied to any other field where a form of energy is transferred between a source and a load. Impedance Matching issues can be analysed as trajectories on the Smith Chart, where the addition of a series or shunt component moves the total impedance along constant impedance, admittance, or resistance circles. If the task is to match the specific impedance to a reference impedance (generally to $50 \Omega$ ), then the target of the impedance matching is to arrive at the centre of the Smith Chart by moving along the arcs from the initial point. If the task is to provide impedance matching to impedance other than the reference impedance, then the end point of the matching trajectory must be the conjugate of the target impedance. Compact Multiband Micro strip Antenna Smith Chart Shown in below.

The closer an Impedance Matching trajectory comes to the edge of the Smith Chart, the narrower the bandwidth. Maximum bandwidth for a given matching network can be obtained by keeping the trajectories short, well away from the edges of the Smith Chart, and as close as possible to the real axis.

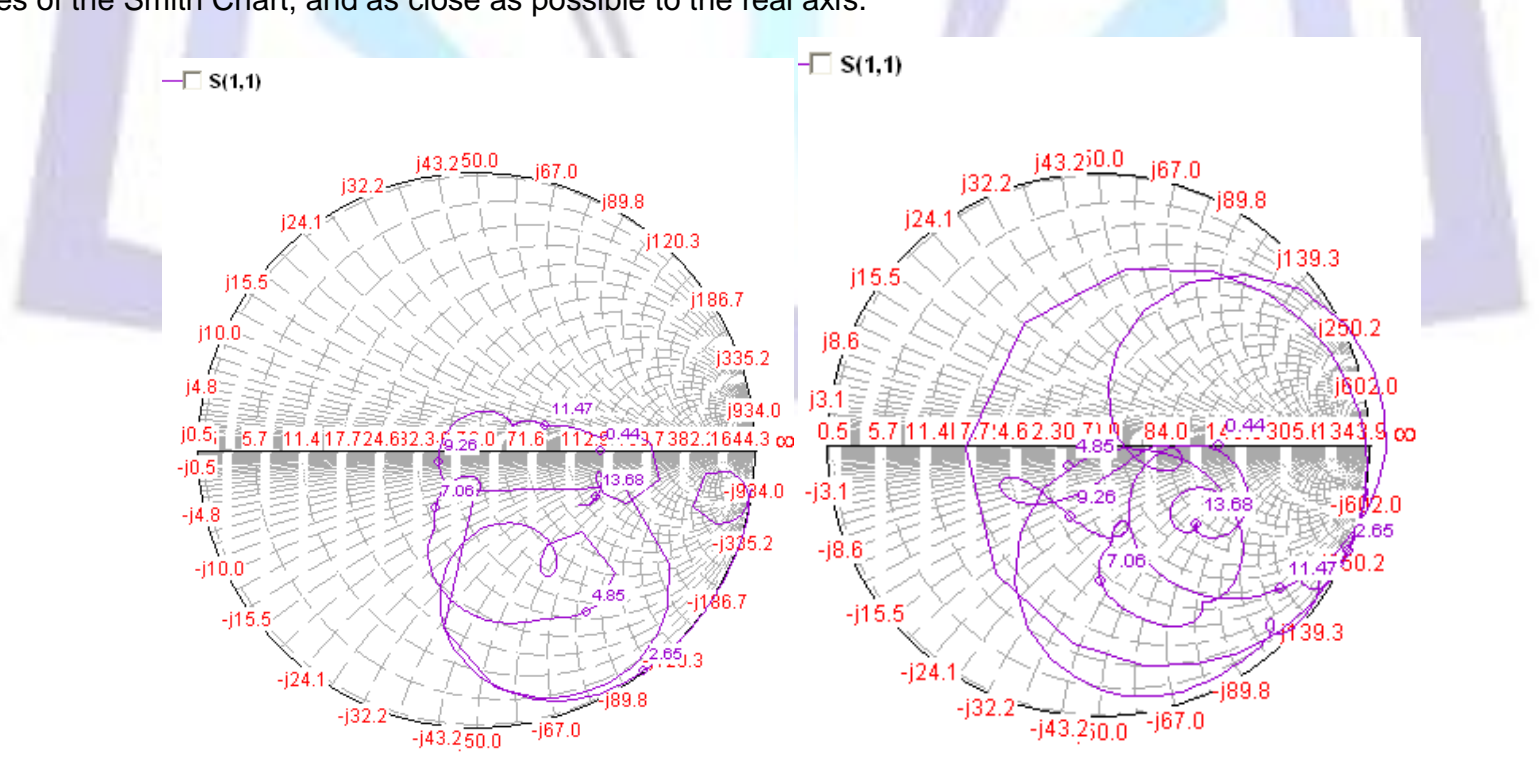

Figure1. Smith Chart Antenna 1 and Antenna 2 
3. COMPACT RECTANGULAR MICROSTRIP ANTENNA WITH AND WITHOUT MODIFIED GROUND PLANE

3.1 Analysis of Antenna 1.

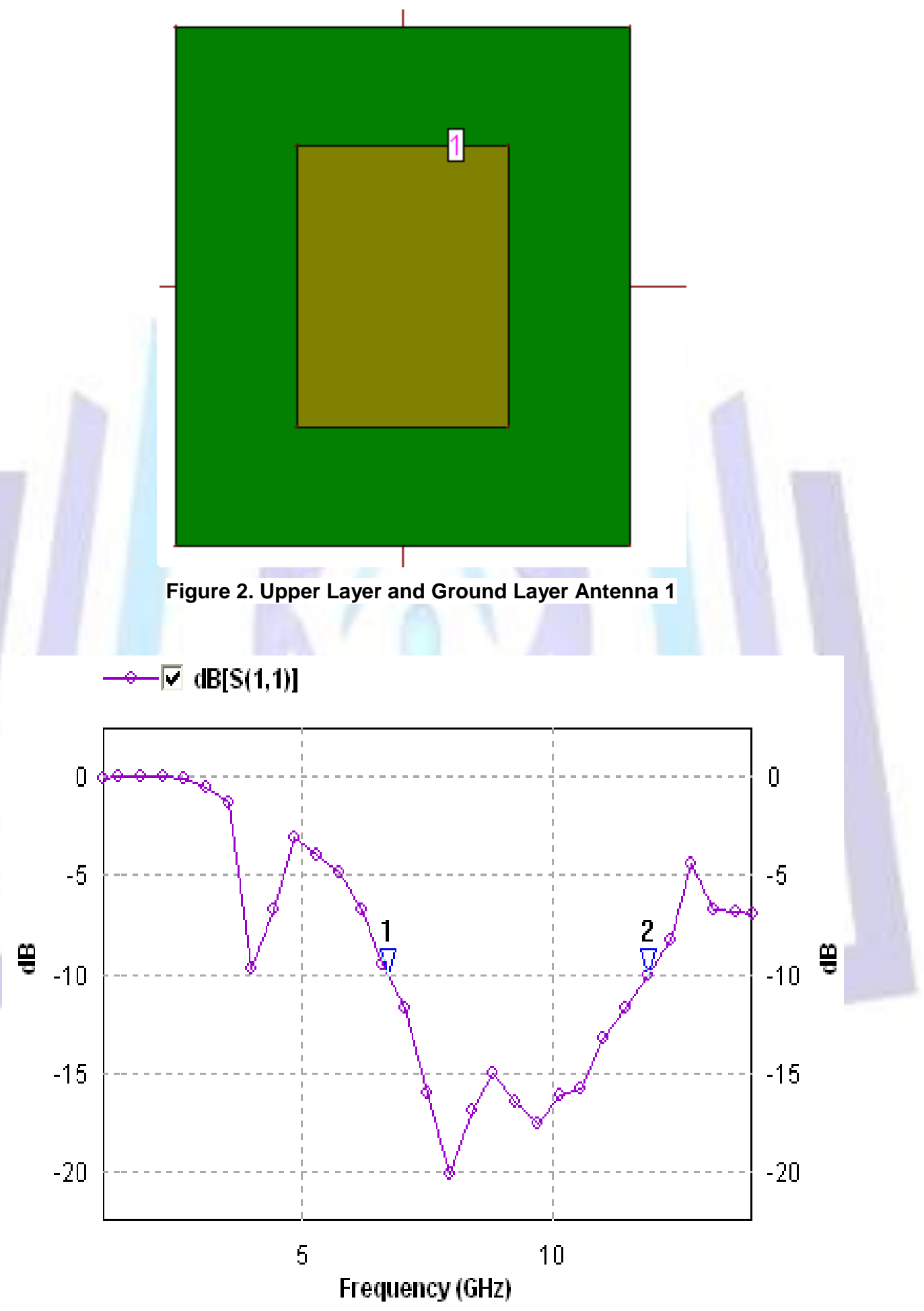

Figure 3. Return Loss of Broadband Multiband Antenna 


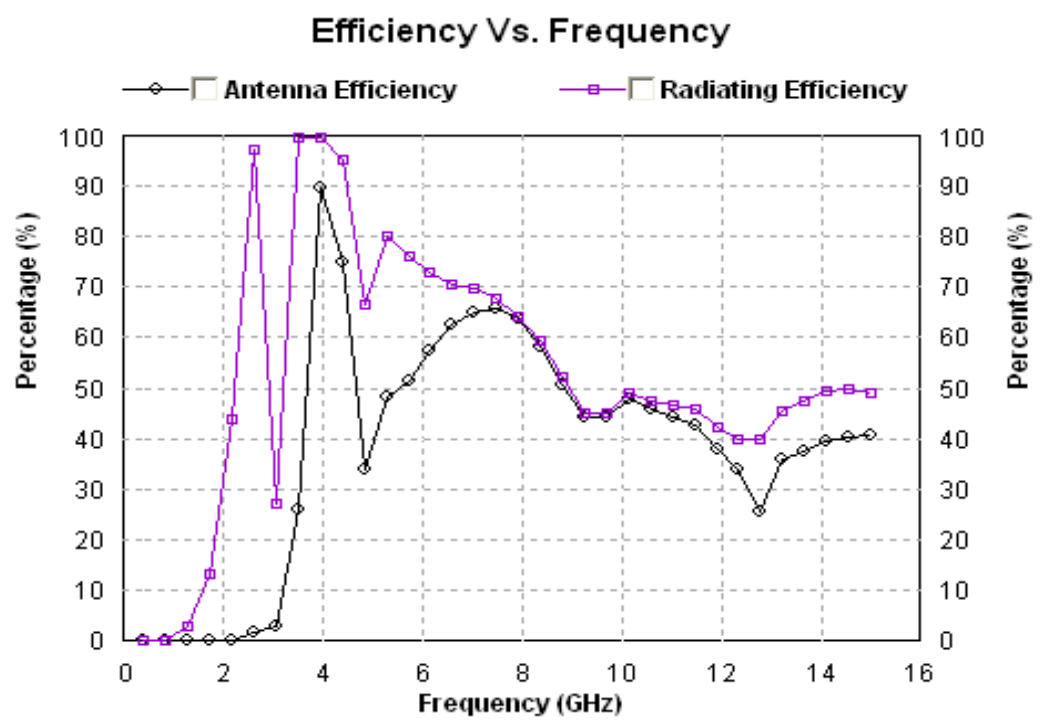

Figure 4. Graph of Axial Ratio Vs. Frequency of Multiband Antenna

Total Field Gain vs. Frequency

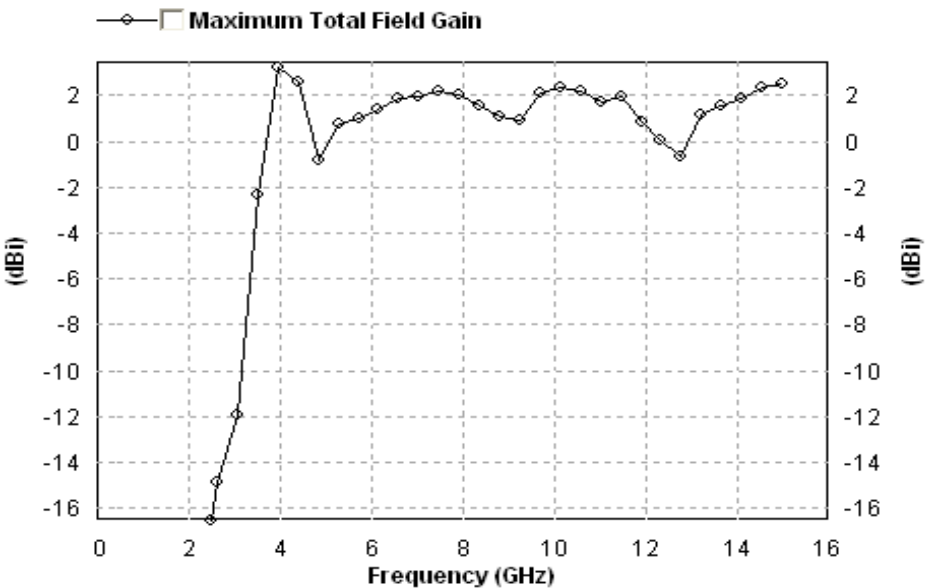

Figure 5. Graph of Efficiency Vs. Frequency of Multiband Antenna

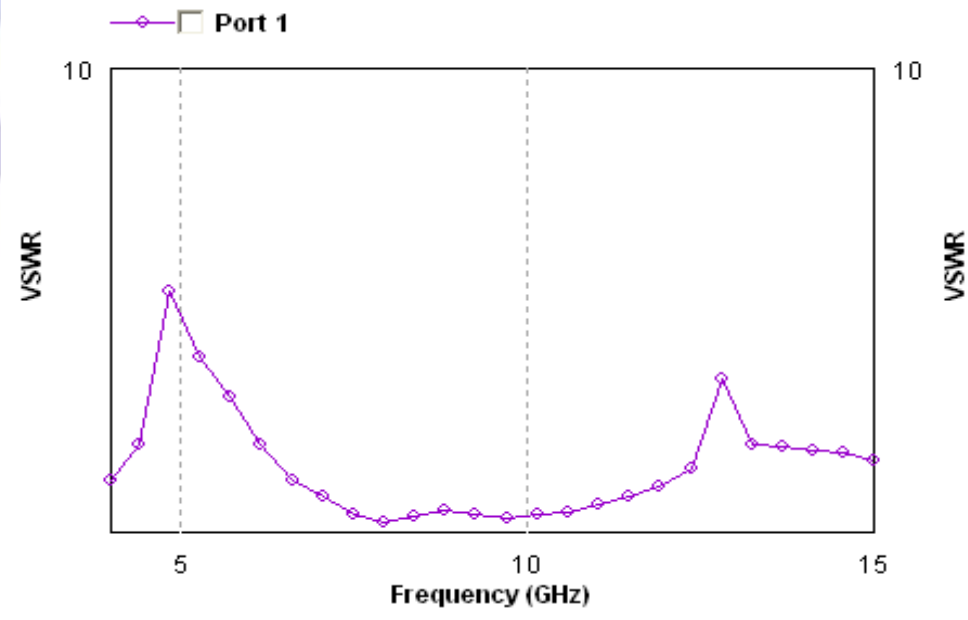

Figure 6. Graph of VSWR of Multiband Antenna 
3.2 Analysis of Antenna 2.

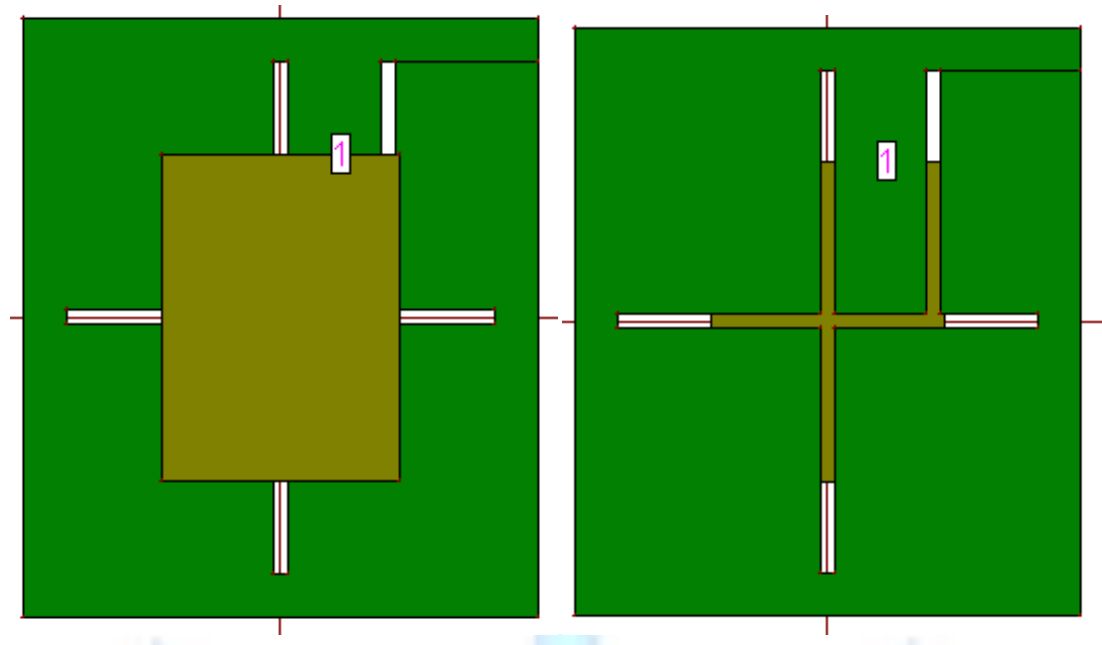

Figure 7. Upper Layer and Ground Layer Antenna 2



Figure 8. Return Loss of Multiband Antenna

Axial-Ratio Vs. Frequency

$\multimap \Gamma$ Minimum Axial-Ratio

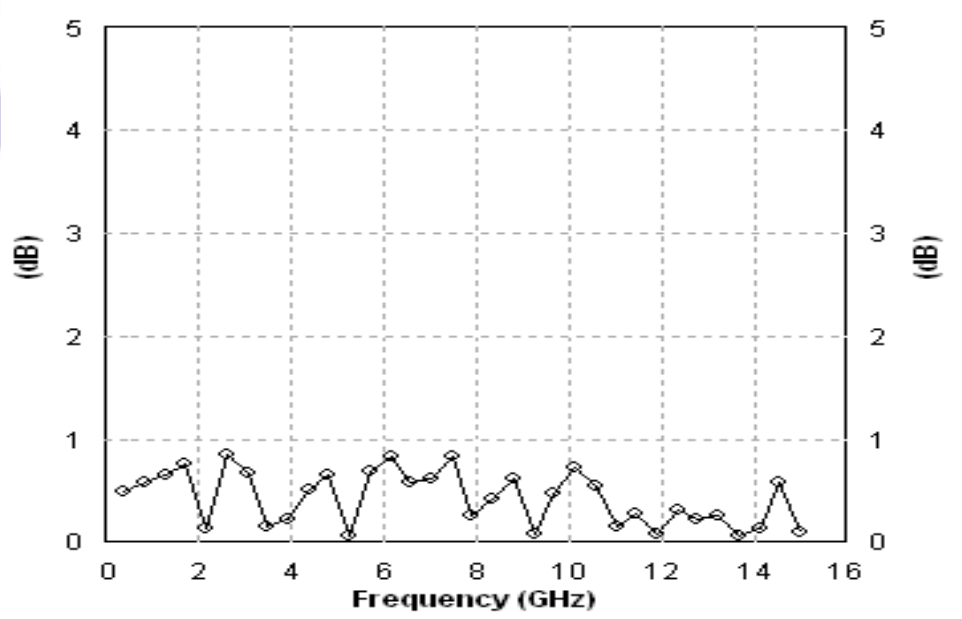

Figure 9.Graph of Axial Ratio Vs. Frequency of Multiband Antenna 


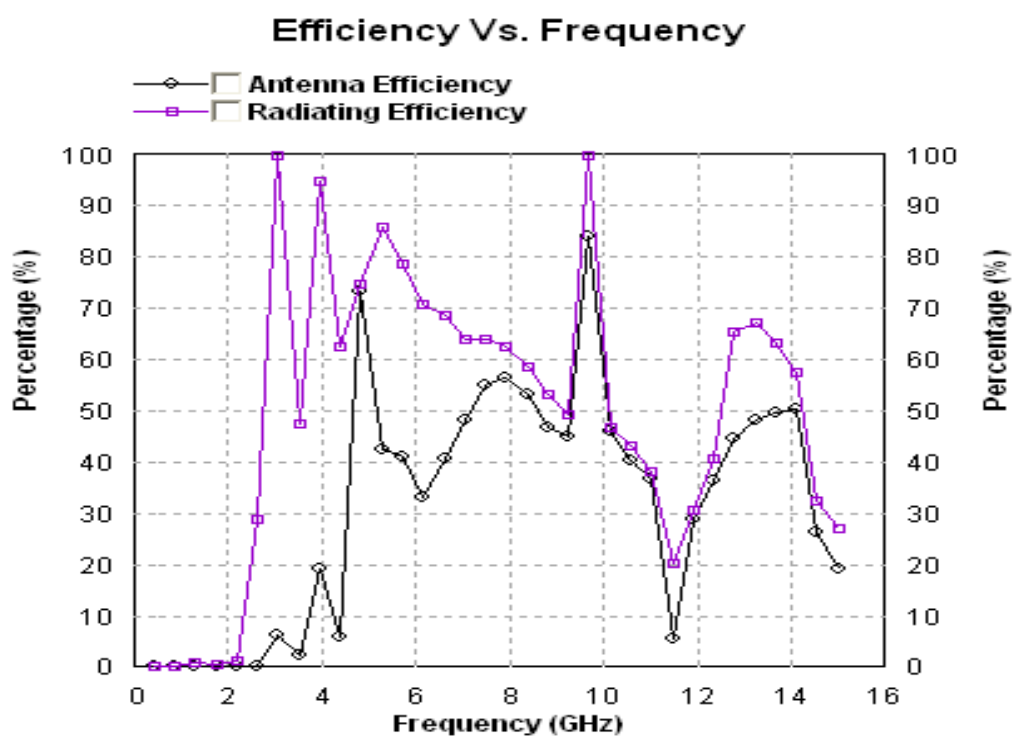

Figure 10.Graph of Efficiency Vs. Frequency of Multiband Antenna

Total Field Gain vs. Frequency

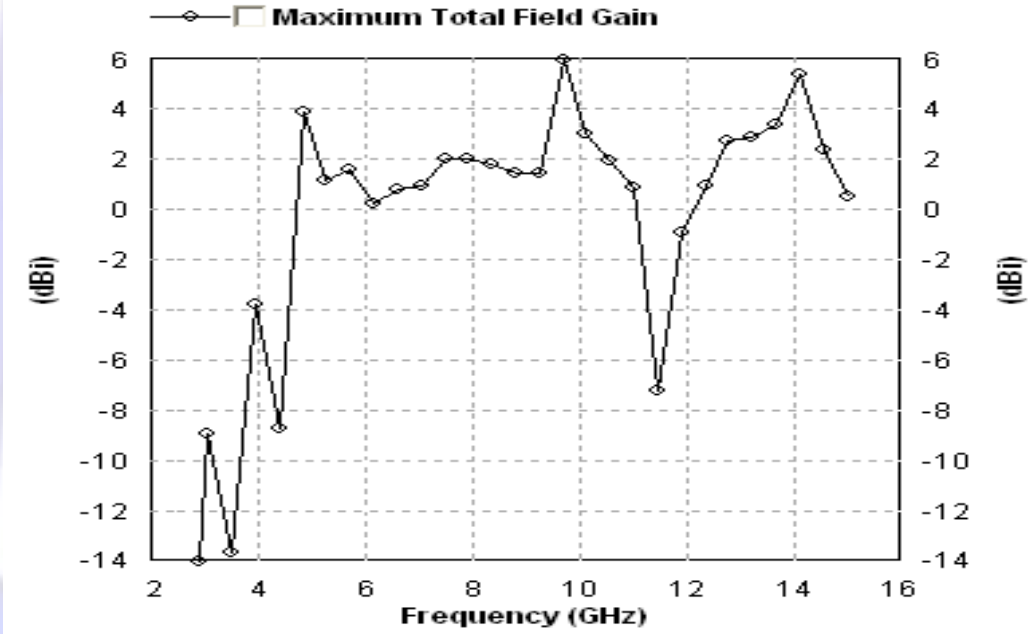

Figure 11.Graph of Total Field Gain Vs. Frequency of Multiband Antenna

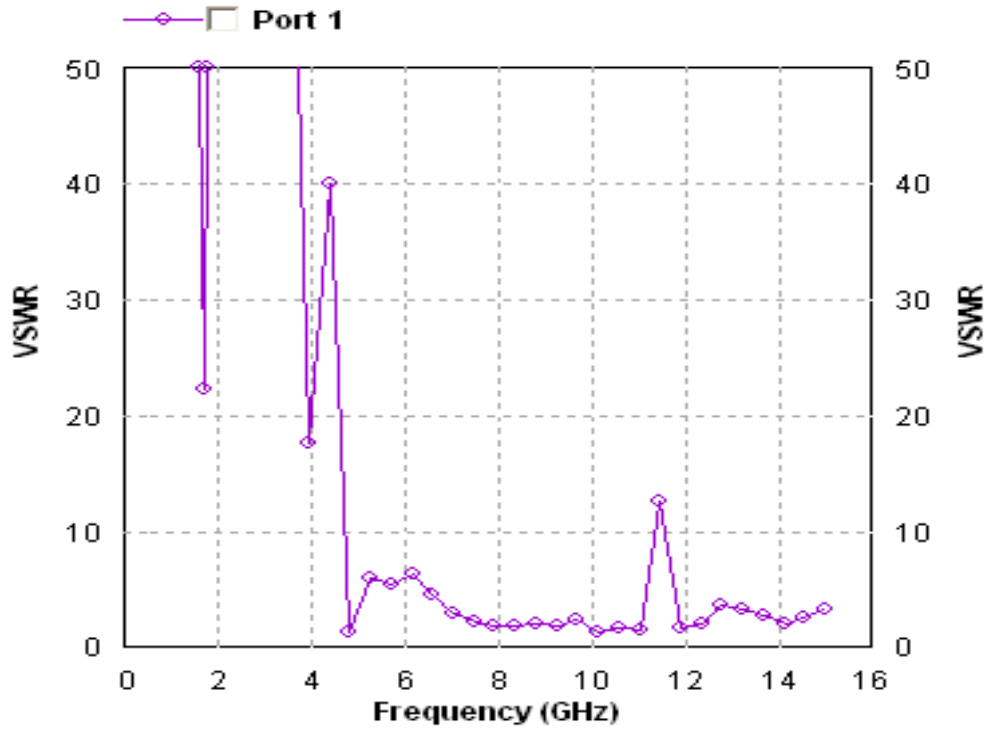

Figure 12.Graph of VSWR of Multiband Antenna 


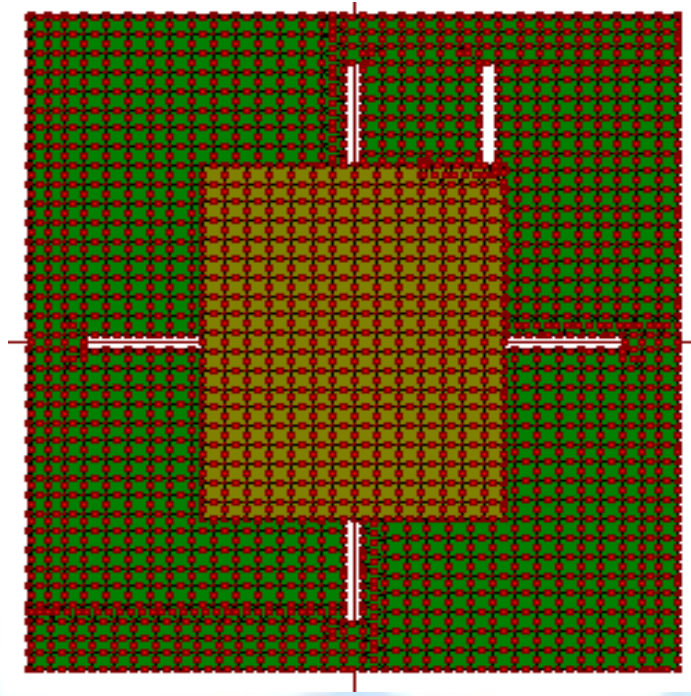

Figure 13.Graph of Meshing of Multiband Antenna

\section{OUTCOMES AND DISCUSSIONS:}

From the Simulation result of Antenna 1 and Antenna 2, it is observed that Antenna 1 is a compact Broadband Microstrip Antenna which bandwidth is $55 \%$. And it works in $6.71445 \mathrm{GHz}$ to $11.9362 \mathrm{GHz}$. (Broadband Multiband Antenna) and also useful in $\mathrm{C}$-band and $\mathrm{X}$-band Application. The result shows that the return loss of $-20.08 \mathrm{~dB}$ is achieved at the resonant frequency of $7.941 \mathrm{GHz}$, From Antenna2-it is observed that, in $4.85 \mathrm{GHz}, 8.382 \mathrm{GHz}, 9.265 \mathrm{GHz}, 10.15 \mathrm{GHz}$, and $11.91 \mathrm{GHz}$ resonance frequency the impedance bandwidth (VSWR $\leq 2$ ) below $-10 \mathrm{~dB}$ return loss obtained are $405 \mathrm{MHz}$, $552 \mathrm{MHz}, 331 \mathrm{MHz}, 1.3645 \mathrm{GHz}$ and $4.57 \mathrm{GHz}$. The proposed multiband antenna consists of a single layer patch antenna with two parallel slots designed in Ground Plane. The result shows that the return loss of $-16.97 \mathrm{~dB}$ is achieved at the first resonant frequency of $4.853 \mathrm{GHz},-10.30 \mathrm{~dB}$ at the second resonant frequency of $8.382 \mathrm{GHz},-10.73 \mathrm{~dB}$ at the third resonant frequency of $9.265 \mathrm{GHz},-17.38 \mathrm{~dB}$ at the fourth resonant frequency of $10.15 \mathrm{GHz}$ and $-12.37 \mathrm{~dB}$ at the fifth resonant frequency of $11.91 \mathrm{GHz}$. From the Simulation result of Compact Multiband Antenna of Axial Ratio, Total Field Gain, Radiation Efficiency and Antenna Efficiency, and VSWR are shown in Figure 3,4,5,6 and Figure 7. IE3D is employed to analyse the proposed antenna and simulated results in return loss, Axial Ratio, Total Field Gain, and VSWR plot is presented.

\section{CONCLUSION:}

A compact broadband microstrip patch antenna-1 has been designed for X-band applications communication systems The reflection coefficient is below $-10 \mathrm{~dB}$ from $6.71445 \mathrm{GHz}$ to $11.9362 \mathrm{GHz}$. The performance is more than meeting the demanding bandwidth specification to cover the $6.71445-11.9362 \mathrm{GHz}$ frequency band.from the simulation results we achieve $55 \%$ impedance bandwidth $(6.71445-11.9362 \mathrm{GHz})$ from antenna 1, obtained impedance bandwidth notch and achieve multiband $8 \%(4.66724-5.07243 \mathrm{GHz}), 6.7 \%(7.95-8.50), 3.5 \%(9.04591-9.37731 \mathrm{GHz}), 13 \%(9.8049-11.1694 \mathrm{GHz})$, $3.7 \%(11.817-12.2742 \mathrm{GHz})$ from antenna-2. At the same time, the antenna is thin and compact with the use of low dielectric constant 4.4 substrate material. And A compact Multiband microstrip patch antenna-2 has been designed for Cband Application and X-band applications. It provides guidance on the design and optimization of double cross slotted in finite ground plane with simple microstrip patch antenna. Comparing between antenna 1 and antenna 2; antenna 1 design for compact broadband antenna for X-band applications and antenna -2 is design for compact multiband Antenna for Cband application and X-band application. Excellent agreement the simulation results is obtained.

\section{REFERENCE:}

[1] C. A. Balanis, Antenna Theory and Design, $3^{\text {rd }}$ Edition.

[2] V.-A. Nguyel, R.-A. Bhatti and S.-O. Park, "A simple PIFA-based tunable internal antenna for personal communication handsets," IEEE Antennas Wireless Propag. Lett., vol. 7, pp. 130-133, 2008.

[3] N. Behbad and K. Sarabandi, "Dual-band reconfigurable antenna with a very wide tenability range," IEEE Trans. Antennas Propag., vol. 54, no. 2, pp. 409-416, 2006.

[4] Raja Abdullah, D. Yoharaaj, "Bandwidth Enhancement For Microstrip Antenna In Wireless Application”, Modern Applied Science Journal, VOL. 7, NO. 6, November 2006. 
[5] http://en.wikipedia.org/wiki/C band.

[6] Abdelaal, M.A.; Ghouz, H.H.M., "Novel compact broadband and dual-band patch antennas," Wireless Communication Systems (ISWCS), 2012 International Symposium on ,pp.890,894, 28-31 Aug. 2012 doi: 10.1109/ISWCS.2012.6328496

[7] Datta, B.; Das, A.; Kundu, A.; Chatterjee, S.; Mukherjee, M.; Chowdhury, S.K., "Twice-band irregular rectangular cut-in microstrip patch antenna for microwave communication," Information Communication and Embedded Systems (ICICES), 2013 International Conference on ,pp.598,602, 21-22 Feb. 2013 doi: $10.1109 / \mathrm{ICICES} .2013 .6508388$

[8] Kushwaha, R.S.; Srivastava, K.; Dhupkariya, S.; Saini, J.P.; Prasad, K., "Slot loaded electromagnetically coupled microstrip line fed microstrip patch antenna for wideband applications," Communications and Signal Processing (ICCSP), 2013 International Conference on ,pp.1082,1086, 3-5 April 2013.

[9] Bimal Garg, Rahul Tiwari, Ashish Kumar and Sunil Kumar Thakur, "Design of Broadband Rectangular Microstrip Patch Antenna Inset 'L' Shaped Feed with Rectangular 'L' Slots in Ground Plane," International Journal of Computer Applications Volume 29 Number 1(ISBN: 978-93-80864-72-0) 1-4, September 2011. DOI No. 10.5120/3532-4818Published by Foundation of Computer Science, New York, USA.

[10] Rahul Tiwari and Seema Verma, "Design Slotted Patch Antenna on Layer 1.6mm", International Journal of Computer Applications Volume 85 Number 19 (ISBN: 973-93-80879-79-1) 1-4, January 2014. DOI No. 10.5120/15091-8035 Published by Foundation of Computer Science, New York, USA.

[11] Rahul Tiwari and Seema Verma, "Inverted L Slot Wideband Rectangular Microstrip Patch Antenna”, International Journal of Advanced Technology and Engineering Research Volume 4, Issue 1, Page No. -27-32, Jan. 2014.

[12] Rahul Tiwari, Preeti Agrawal, Sunil Kumar Tripathi and Richa Sikarwar, "Improving Bandwidth In RMPA Using 'U' Shaped Slotted", International Journal of Advanced Technology and Engineering Research Volume 2, Issue 4, Page No. 211-214, July 2012.

[13] Bimal Garg, Rahul Tiwari, Ashish Kumar and Tilak Chitrance, "Design of Factored ' $X$ ' Shaped Metamaterial Structure for Enhancement of Patch Antenna Gain," Presented at IEEE International Conference on CSNT-2011 held on 3-5 June, 2011 at SMVDU, Katra, Jammu, and Organized by 'MIR-LAB' Society Page(s): 232 - 235, EISBN :978-0-7695-4437-3,Print ISBN:978-1-4577-0543-4,INSPEC Accession Number:12139368, Digital Object Identifier :10.1109/CSNT.2011.57,available on IEEE Xplore.

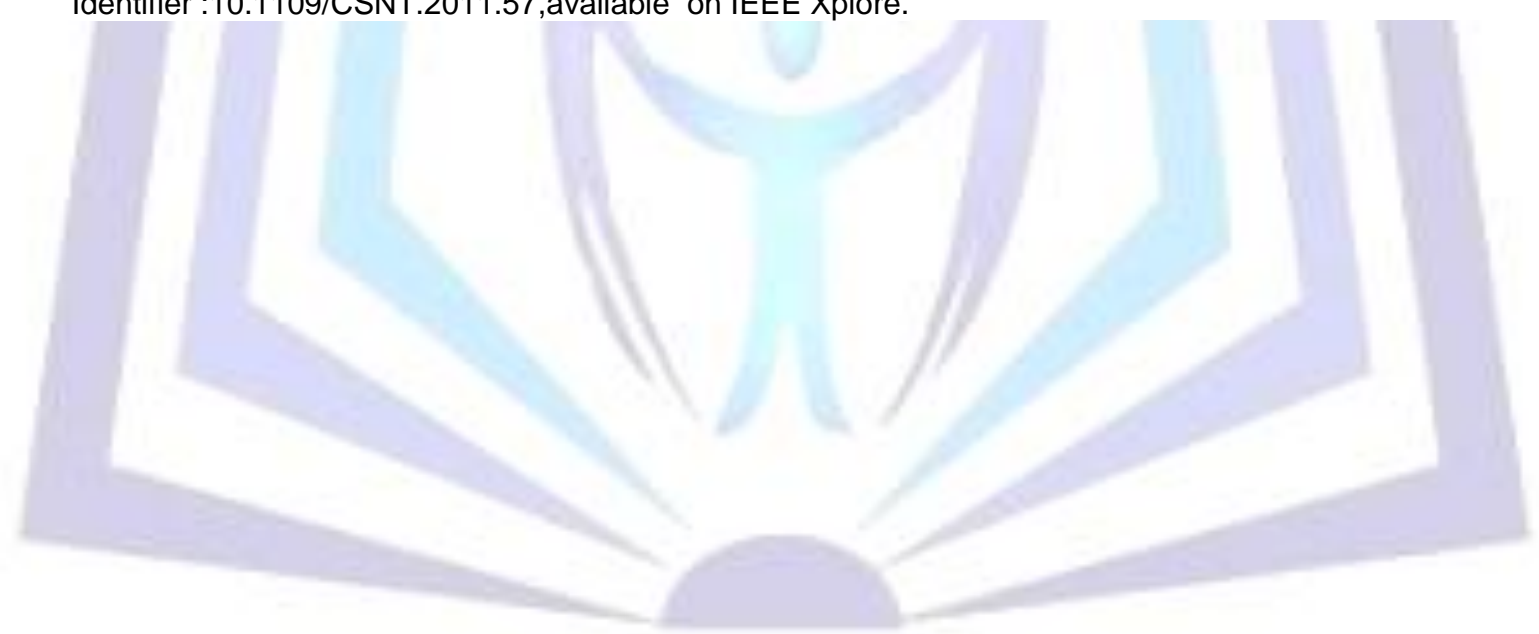

